\title{
Forum: Identity - Discussing a Vague Concept
}

Comments on Jean-Claude Kaufmann's 'Identity and the New Nationalist Pronouncements' (IRSR Volume 1, Issue 2, pp. 1-13) by Andrea Spreafico, Richard Handler and Doris Bühler-Niederberger and a rejoinder by Jean-Claude Kaufmann.

\section{Comment}

\author{
Andrea Spreafico \\ University of Perugia
}

Kaufmann's books have been examining the issue of identity in a very prolific way for several years. Here he offers a clear description of some of the most important challenges that today's identity beliefs - religious and nationalist for example - pose to modernity. In this commentary, however, I would like to consider some basic aspects of the reasoning that emerges from his latest article. In particular, I will focus on his personal conception of identity and try to follow his spirit. In this way I will attempt - even if only through some fleeting thought - to contribute to probe and structure the debate on a notion that is often misused by researchers. It seems to me that sociology is now faced with the need to pay greater attention to the contributions, albeit quite divergent, offered by other disciplines (i.e. philosophy of the mind, mind sciences, linguistic anthropology and, above all, ethnomethodological sociology) in order to better understand the dynamics that sociologists describe using the term 'identity'.

According to the point of view I would like to unpack - as a stimulus to a discussion that has also (perhaps unfortunately) political implications - Kaufmann at times appears as the most evolved and reformative pole of an overall still 'traditional' way of considering identity. It is true that in Europe various politico-cultural formations oppose more and more e-mail: spreafico@mclink.it. 
frequently the referral to presumed 'identitary' elements with no attempt at qualifying them or delineating their actual content (there is a superficial reference to 'adversarial identity', almost without qualifying actual content, both right and left of the political spectrum, which finds in the us-them opposition a primordial and only temporary boost to identification). However this is one of the not so new games allowed by the diffusion of the potentially dangerous idea that individual identity exists and has a substantial nature. It is an idea deeply rooted in the nature of humans - for biological, cultural and historical reasons, and for simplification of the context of action - that even scholars have difficulty dealing with, since it is part of the background of common sense in which they live and in which they have been brought up. It is an idea that finds its worst outlet in its collective dimension (perhaps not necessarily qualified as religious), inevitably totalizing, and that might instead try to be controlled (some would say 'broken down') piece by piece, especially in his individual version. This is an endeavor that can be attempted, even if not successfully, in order to become aware of the artifice on which this idea is partially based, or, even more worthy, to remember indirectly that sociology's task is to describe how - and not why - interaction occurs and, above all, that this task does not indicate a shared objective on which to converge, for example how societies should be (identity has also been the instrument through which intellectual currents have abandoned their scientific goals and, before or after, turned to political ones).
The competition of 'us' against 'others', well-described by Kaufmann, leads to a sterile conflict, nonrepayable, unable to build and understand the reality of cooperation, also because taking for granted the existence of an artificial construction which produces clear boundaries (first those between the single individual, the environment that surrounds him and other individuals), and therefore inevitably generates domination, that is the individual identity. For example: if we conceive ourselves as completely distinct, we can interact placing the group interest after that of the individual, using the environment only as an inexhaustible means. All that while, if we look at social action from the outside, there is only a succession of shared cooperative actions and interactions where it is not easy to distinguish one individual from another. It is necessary, at this point, to grant attention to the idea deriving from the symbolic-interactionism, that normally interacting persons, albeit within limits, would adopt an uninterrupted reflective attitude regarding the construction of a meaning for their lives necessary to the action (identity would thus be a process that creates momentarily, at any moment, the conditions for action); which means, in fact, extreme intellectualization of human activity, that is, presupposes a notably mentalistic conception of the capacity and conduct of the human agent, who often allows the signifieds - though unclear in the moment - to emerge in the course of the interaction itself. In order to contextualize the debate about what may be referred to as 'individual identity', we may remember the 
ethnomethodological-Wittgensteinian hypothesis, by which there's nothing concrete that corresponds to the term 'identity' beyond the language (a linguistic game). We also may refer to the discussion (e.g. developed by Coulter) about the difficulties and limits of approaches dealing with the problematic of the human agent by considering him as a 'cognitive' being, equipped with a 'mind' and a 'personality', who navigates a social world and uses this 'subjective' equipment in various ways - the theoretical schemes that place the individual human agent at the centre of the scene, by uncritically relying on assumptions of atomistic, psychologistic and cognitivist types, fail, in fact, to show clearly the ways in which social life occurs. But we have at least to remember (here following Liberman) that people function as a group and the local organization of behaviour is an everyday issue made by individuals who act in a 'concerted', co-operative way, and focus on how local work should be done. Only the social is primordial, while the notion of 'individual' emerges from, and is supported by, social practice: the intersubjective dimension precedes the subjective one. The self arises from a system of social practices that sustains and nourishes individualism and thought is something mostly realized collectively.

Subjects are not entities existing prior to actions, they are eventually constituted through doing. Speaking of identity also means deceiving ourselves to believe that we consist of a particular substance distinct from the otherness that instead pervades us. Many more are the arguments (from Pollner to
Parfit) which might help dismantle the pre-supposed idea of an individual and distinct identity, but I will note here, only as a last example (appositely taken from 'tradition'), that in psychology the self can be described as the selfpresentation of the experience and the representation that we have of our own interiority, as the expression of selfconsciousness. In short, the self would correspond to the description of our way of collecting introspectively what we then designate with terms such as 'person', 'psyche' or 'mind', or their parts, with their supposed distinctive features. These self-experiential images are content of consciousness, or more generally of mind (in fact they partially flow back into the unconscious). However the acquisition of self-consciousness remains always precarious, lacking, often partial; self-consciousness is mostly an illusion, a narrative social construction made from forgettings, dismissals, rationalizations, modifications, interested self-deceptions, bad faith, and it constitutes in any case the introspective consciousness of a surface mistaken for a depth. The ability to directly access the interiority, besides being rare in its full form (we monitor and are self-conscious of our interiority only rarely), it is basically a myth: the description of our interiority is culturally variable, harmonizes with the expectations of others and, sometimes, with the self-image one would like to cultivate; moreover, instead of the interior world, we access an imaginary dimension where exist justificative socially conventional constructions. What we call human consciousness, rather than consisting in a continuous cognitive state of 
mind, consists mainly in the ability to re-motivate our actions ex post, i.e. in the ability to 'approve' constantly what we are doing. All mental processes would be thus essentially unconscious and 'automatic', but would then be partially described and justified, in a narrative form, with the help of conventional constructions such as 'choice', 'inspiration', 'intuition', 'will'. The uncertainty of the boundary between conscious and unconscious and the extension of the latter, may call into question the concept of consciousness itself. Identity would thus end up resembling a narrative reappropriation of the products of unconscious cognitive elaborations another reason to be careful about its use.

\section{Comment}

Richard Handler

University of Virginia

In North American social science discourses, and even in broader public discussions, 'identity' became a watchword starting in the 1950s (Gleason 1983), approximately according to the chronology JeanClaude Kaufmann sketches. More particularly, in cultural anthropology, descended in North America from neo-Kantian philosophy and German romanticism through our apical ancestor, Franz Boas, the disciplinary focus on 'culture' began to crumble in the 1980 s, with 'identity' to some extent replacing the prior term. (For example, from that moment to this, far more students have entered the graduate program in anthropology at the University of Virginia with the intention of studying some aspect of identity than those who conceptualize their project in terms of culture.)

In its role as central disciplinary term, 'culture' took more and more of a beating

\footnotetext{
e-mail: rh3y@eservices.virginia.edu.
}

as various mid-century structuralisms gave way to post-structural theories (Handler 1997). Accompanying this change in theoretical fashion were the shifting field experiences of young anthropologists, who perhaps entered the discipline thinking they would study culture, but found themselves in their initial fieldwork studying folks elsewhere who were busy constructing and codifying what they saw as their own culture, often in politically charged post-colonial situations. It was easy enough, at that juncture, for anthropologists to talk more about identity than culture, since the former term seemed to allow them to focus more on actors in the process of creating culture than on the static boundaries and fixed contents often implied in the older, [colonial] culture concept.

Identity has become a global issue, as Kaufmann, notwithstanding his 
focus on fundamentalisms in Europe, suggests. And modernity is the global social formation which underpins identity issues. Like Kaufmann, I have relied on the work of Louis Dumont, as well as on Dumont's own chosen ancestor, Alexis de Tocqueville (Dumont 1965), to understand the cultural foundations of modernity, and in particular, of modern individualism (Handler 2005). The worldview of modern individualism includes these assumptions: that reality is composed of discrete units; that units, whether individual persons or social groups, are neatly bounded; that such units 'have' an identity or unique set of characteristics which distinguishes them from all other units at the same level of analysis; that identity operates evenly within each unit, such that, for example, a person is consistently and fully him- or herself, and that a social group is made up of sub-units (persons) each of which shares equally in the collective identity; and that these units preserve their essential identity as they move through time, which is itself understood in terms of three-tense grammars, that is, past-present-future (cf. Whorf 1941).

Participants in the social formations of modernity can be more or less aware of these ontological assumptions which underpin their everyday world. Anthropologists of the Boasian school speak of reflexivity to indicate people's ability to gain some measure of critical distance from such assumptions. Kaufmann uses the term 'reflexivity' somewhat differently. He speaks of the 'emergence of the subject', that is, of people who are aware that they have the right to choose their way of life (or 'lifestyle', as we now say). But the apparently limitless choices presented by contemporary consumer society can be paralyzing. In Kaufmann's words, 'life becomes a hell of endless questions, which destroys the capacity to act'. This can lead self-reflexive people to choose fundamentalisms of various sorts, precisely so they can escape the hellish dilemma of limitless choice. In his analysis, some people respond to this situation by enclosing themselves in the ideological cocoons of fundamentalist political programs or religions, which provide their adherents with the steady bearings they need to maintain their sanity.

Kaufmann is aware that this psychosocial phenomenon is a modern one: these fundamentalisms are new, which is to say they are structured by modern ideology, despite their putative ancestries. If we scrutinize them from the perspective of a critical cultural anthropology, we see that modern fundamentalisms, like Enlightenment rationality itself, share something like the set of assumptions which I described above. Kaufmann challenges those assumptions by insisting on 'the plurality and plasticity' of identity. And he challenges Enlightenment rationality by showing that its inexorable deployment produces the various 'irrational' fundamentalisms it intended to vanquish, which is another way of saying that both phenomena are moored to the same social formation.

The great Tocqueville made a similar argument, concerning the contradictory effects of modernity, in his discussion of what his theoretical descendants of the 1950s called conformity (which Kaufmann discusses here in terms of norms). Modernity, or democracy, as Tocqueville called it, in principle 
liberated persons to become free and equal individuals. As a free and equal citizen, each person 'feels with pride that he is the equal' of everyone else. Unhappily, however, when this citizen 'comes to survey the totality of his fellows and to place himself in contrast with so huge a body, he is instantly overwhelmed by the sense of his own insignificance'. This sense of helplessness led, Tocqueville argued, to an unprecedented (and ultimately irrational) reliance on public opinion. It was their very freedom and equality that drove citizens of democracies to conform to public opinion, since, in their eyes, "it would seem probable that, as they are all endowed with equal means of judging, the greater truth should go with the greater number' (Tocqueville 1840:11). It is from passages like these that we can read, in Tocqueville's analysis, an outline of the social and ideological mechanisms of 20th-century totalitarianisms, and of the 21 st-century fundamentalisms which Kaufmann diagnoses.

\section{References}

Dumont, Louis. (1965) The Individual in Two Types of Society. Contributions to Indian Sociology 8:7-12.

Gleason, Philip. (1983) Identifying Identity: A Semantic History. Journal of American History 69:910-31.

Handler, Richard. (1997) Interpreting the Predicament of Culture Theory Today. Social Analysis 41[3]:72-83. (2005) Critics Against Culture: Anthropological Observers of Mass Society. Madison, WI: University of Wisconsin Press. Tocqueville, Alexis de. (1840) Democracy in America, vol. 2. Trans. Henry Reeve. New York: Knopf [1954]. Whorf, Benjamin Lee. (1941) The Relation of Habitual Thought and Behavior to Language. In Language, Thought, and Reality, pp. 134-59. Cambridge, MA: M.I.T. Press. 


\title{
Comment: Identity - danger or social resource?
}

\author{
Doris Bühler-Niederberger \\ University of Wuppertal
}

Identity is hard work - this is what JeanClaude Kaufmann tells us in his article. Such work becomes necessary if the social belongings of the individual - i.e. his/her inclusions in social collectivities - are no more sufficient to convey meaning to his/her actions and existence. It is a never ending work, because the very processes of reflection which are meant to build identity put it into question as well.

Kaufmann gave us marvelous insights into the laborious work of identity, e.g. in his books on how couples try to share their work around doing the laundry (1992) or on how cooking and meals are made an integrating element of family life, mostly by the wives (2005). These are the two of his numerous ethnographies of everyday life which I like most, as they allow microscopic insights into an individualized society, showing that individualization is not at all a process beyond class or gender, i.e. beyond belongings to status groups, rather it is a process which we might call an identification with one's class and gender status, a personal appropriation of the possibilities and the limits of such status. Let's have a closer look at Agnès' and Prune's solutions concerning everyday routines to give some evidence for this assertion - two stories in Kaufmann's ethnographies. Agnès - although she had been rebellious against her overly accurate mother - became a very perfect housewife once she was married. But she did not loose her zest for another life, and she celebrates a little revenge: She regularly waits until the very last moment to iron her husband's shirts. She does it only in the morning, shortly before he has to leave. This happens several times a week and he regularly becomes upset, but she calms him that everything will be ready in time - and she admits to find quite some pleasure in this game. As to Prune, she is obsessed by the idea to continue her rural family tradition. That is why she abstains from modern techniques to cook, from anything like canned or frozen food and prefers her old cast-iron pan and she believes in taking much time for the preparation of meals. This is how she wants to devote herself to the family for the sake of a real happy family life. But, on the other hand this whim as well bothers her, especially on Sundays. Then, the whole family is at home and she can not spend her time with them, as she is busy in the kitchen. She solves her conflict by preparing fast dishes on Sundays - of all things the weekend meals, the highlights of a traditional family life; she is in a quandary.

While such solutions may be looked at as 'individual' and 'unique', and their proud inventors may take them to fit into their draft of personality, it is nevertheless obvious that the

•e-mail: buehler@uni-wuppertal.de. 
'individuality' concerns only details of these solutions. To state it very clearly: beside some minor quirks these results of identity work processes fit perfectly to the status configuration of their 'creators'. Firstly, they conform to the norm that women are responsible for most of the work in the household in most families and couples. Secondly, they prove to be lower middle class solutions, corresponding to the norms of proper family life of this social group and to the economic possibilities which do not allow to employ a maid. The scope of possible solutions in this French sample is probably even narrower than in would be in a nonWestern society, as the values of good parenting in Western middle classes also do not allow to delegate a substantial part of household and care work to the children, as it might be done in many countries of Asia or Africa. Nevertheless such solutions are, and this is important, interpreted by the persons in Kaufmann's studies as solutions that fit to their concepts of themselves and overall to their attitudes and preferences.

The reader may smile in a mixture of compassion and derision about the endless endeavour of these women and men to convey meaning to their actions, and probably he/she will not see such daily 'identity grind' to be much of a pressing problem of society as a whole. But, in Kaufmann's rationale the matter is much more serious! These games of identity are not only the somewhat tiring content of communication and disputes in couples and families, not only endless stuff to discuss among friends, they are ,crucial for the future of our planet' - this is stated clearly by Kaufmann in his article.
Kaufmann assumes a highly menacing side to these identity processes: People and especially the ones whose social positions do not guarantee much social recognition, who have no multi-faceted social networks to rely on in their identity work may find refuge in totalitarian solutions, locking in the whole of their personality. Such solutions relieve the individual from being frightened and tired of himself. But, as they are totalitarian and often aggressive they are a danger for the individual himself as well as for the democratic society. That is Kaufmann's argumentation and besides religious groups he mentions populist and right wing parties as examples of movements which make such identity offers. - We find in such argumentation a very common sociological distrust concerning an individual who is only weakly guided by social definitions and obligations. Such an individual is taken to be overstrained by the autonomous planning of his decisions and his social affiliations. This has been told to us by Émile Durkheim already, and we find it in recent years in the publications of German social scientists like Ulrich Beck, Ronald Hitzler, Wilhelm Heitmeyer - the list might be continued.

I want to make two objections against this sociological common sense concerning the danger of individualization. Firstly, identity work is a resource, and this is even true for individuals which are rather disadvantaged. This is what our empirical research about the biographical planning of young people showed. It was most important for the young people to work out a 'self- 
project', i.e. to make occupational choices they can really identify with. They also often anchored their choices in what they had already wanted and aspired for since a long time - even in what they had wanted since they had been a child. Such a biographical anchorage proved to be a capital they could use to overcome difficulties during apprenticeships or study programs and to stick to their choice. Astonishingly enough, young people who chose professions with low prestige proved to be no less self oriented than university students. Such self-projects - although mainly a phenomenon of an individualized society - are socially structured, i.e. aspirations and decisions of young people depend clearly on the social status of parents and for some social groups they become therefore also a self-limitation of aspirations. Nevertheless, they are a resource young people rely on (BühlerNiederberger/König 2011).
Secondly, the success of totalitarian ideas and movements - either religious, ethnocentric, or nationalist - can not be explained as an 'individual problem'. Not an overcharged individual loosely controlled by society is the true problem, but histories and even continuation of violence, of bad regimes, of corruption, and highly unbalanced distribution of goods provide the fertile soil for such success. This success has to be explained in other terms than the one of identity search: in terms of social conflict, of power and economic injustice.

In what way and with which wins and losses for themselves and for society do individuals cope with the requirements and chances of modern societies to plan their life, and to convey meaning to actions and decisions? This remains a question that has to be carefully investigated and not be answered on the basis of sociologists' distrust against the individual.

\section{References}

Kaufmann, Jean-Claude (1992) La trame conjugale. Analyse du couple par son linge. Nathan: Paris.

Kaufmann, Jean-Claude (2005) Casserolles, amour et crises. Hachette: Paris. Bühler-Niederbeger, D., König, A., (2011) Childhood as a resource and laboratory for the self-project. Childhood, 18, 180-195. 


\title{
Rejoinder: Discussing a vague concept
}

\author{
Jean-Claude Kaufmann` \\ National Center of Scientific Research (CNRS) \\ University Paris Descartes, The Research Centre on Social Relations CERLIS
}

I conducted research on identity over the past ten years, which enabled me to see how difficult it is to discuss this concept scientifically. This is because sometimes it carries with it too much passion and ideology and other times because the definitions are not the same between interlocutors, and because everyone places a different content in the term. (I particularly remember a series of lectures and debates in Tunisia and Algeria where, despite everyone's goodwill, it was impossible to truly understand each other and exchange information.)

Faced with such a vague concept, a first option would be to try to approach it through scientific debate, and to rely on the more strongly established concepts or data. But this would further accentuate its vagueness, and unleash potentially dangerous social uses. Confronting various conceptions of identity is the focus of considerable social and political issues, and it is for this reason that social sciences should not turn away from this issue, but rather try to clarify the terms of discussion. Like it or not, and although it is often difficult, we must try to scientifically discuss identity and identity stakes today. So I thank my three colleagues, who accepted this challenge.

The contribution of Andrea Spreafico illustrates in a striking way precisely how misunderstandings can be frequent in the debate. Because the positions he attributes to me are not mine, I do not recognize myself in his criticisms, and on the contrary, I range myself on the side of most of the proposals he develops: that the identity has no substantial reality; it is the basis on which I have always written about this notion - that identity production creates the conditions for action: this is what I discussed in my book, The invention of self, an identity theory. That the individual is not a block, separated from the social, but the result of a web of different processes: this is especially the central thesis that I developed in a theoretical book, Ego, towards sociology of the individual, in 2001. Even when Andrea Spreafico calls for more interdisciplinary work I can only be surprised, precisely I since work at the crossroads of disciplines: sociology, ethnology, psychology and history. He talks about the philosophy of mind and cognitive sciences? Precisely I use them extensively (especially in a book, Quand je est un autre [When I is another]), relying on the work of Daniel Denett, David Chalmers or Thomas Metzinger, to develop the idea, dear to Andrea Spreafico, that the self does not exist as a given entity, it is a construction, constantly changing at the intersection of innumerable social and cognitive processes.

To sum up, I cannot respond to the criticism of Andrea Spreafico as it is addressed to a given position which

e-mail: j-c.kaufmann@wanadoo.fr. 
appears to me as being opposite to mine. The idea that the self does not exist as an entity is inconceivable for the individual himself. One cannot live without representing oneself existing as a subject. So he invents a fiction, all-encompassing, creating at all times the evidence of the sense that builds him. It is an illusion of course, very far from the anthropological reality, but it is a necessary illusion. This is the heart of the process of identity: to produce this totalizing illusion, which creates a sense of self and the conditions of the action.

Production of identity does not work like the anthropological reality; its operating model is almost the opposite. That is why I make more and more the distinction between the anthropological reality of the individual (made at the articulation of many contradictory processes) and identity. Andrea Spreafico thought that I too was talking about the individual himself. That explains the confusion. I only spoke of identity in my article, the identity, which for me is a subjective production, creating the illusion of a whole self.

The separation individual/identity is historically new; it is an invention of modernity, with an emphasis on this separation of only half a century. This is well observed by Richard Handler, and I thank him for his fine text. It rightly points out that we owe everything in the analysis of modern individualization (which propels the identity issue at the front of the stage) to Tocqueville or Louis Dumont. He also rightly points out to the issues related to the development of reflexivity in late modernity (regardless of the precise definition that is given to this reflexivity). In my opinion, once again, on the mental level, the reality of the individual divides into two, referring to two opposing operating models. While in the reflexive logic, the individual engages in a scientific cognitive activity: he collects information, evaluates, compares, takes a critical look upon himself, he calls into question the evidence obtained, multiplying the parameters and the unanswered questions. However, these are parentheses that one must close in order to represent oneself as an entity and be able to act. Here comes the subjective production of a totality of meaning, which I personally call identity.

I also thank Doris BühlerNiederberger who kindly refers to my anthropological investigations, which are the precise basis from which I develop my theories on identity. As Richard Handler, she rightly refers to the individualizing modernity by highlighting the positive aspects of the process of identity, subjectivity at work, ability of the individual to define and invent himself despite the burden of social determinations. I agree with her remark. My article highlights one minor aspect (when the identity process reaches dead ends, potentially dangerous) without sufficiently stressing that this is a deviation and not the whole process. But I thought it was important to point out this phenomenon, including its most extreme manifestations.

I realize that this brief response will not suffice to clarify everything. We must be patient, and set the terms of debate step by step. The stakes are high, and they are not only scientific. 
Unauthenticated 